\title{
The Importance of Scanning Electron Microscopy (SEM) and X-ray Microanalysis (EDS) in Determination of Gunshot Residues (GSR) in Human Hands
}

\author{
P. H. A. Aragão ${ }^{1}$, L. E. G. Bucharles ${ }^{2}$, J. C. Spadotto ${ }^{1}$, A. R. N. Rodrigues ${ }^{1}$, V. B. Motta ${ }^{1}$, \\ B. M. Biazin ${ }^{1}$, A. G. de Oliveira Junior ${ }^{3}$ and C. G. T. de Jesus Andrade ${ }^{3}$ \\ 1 . Department of Physics - Universidade Estadual de Londrina, Londrina (PR) - Brazil \\ 2 . Institute of Criminalistics - Polícia Científica do Paraná, Londrina (PR) - Brazil \\ 3 . Department of Biology - Universidade Estadual de Londrina, Londrina (PR) - Brazil
}

One of the most important properties of the SEM is its ability to combine image with elemental microanalysis. The SEM has become an indispensable tool in forensic investigation due to its ability to examine a wide range of materials in detail, from high to low magnification with an exceptional depth of focus. One of the most well-known applications of SEM in forensics is the automated detection and classification of GSR. GSR is composed of burnt and unburned particles from the propulsive charge and primer components from the bullet, the cartridge case and the fire arm itself [1]. GSR is formed by the rapid condensation of metals vaporized during shooting. Particle analysis can identify individual gunshot residue particles through both morphological and elemental characteristics. When certain particles are detected on the collected sample, the analytical results can be interpreted following rules of a formal general interpretative system, to determine whether they come from the explosion of a primer or from other possible sources. For the assessment of the value of a GSR in linking a suspect to a crime, it is important to compare two hypotheses: the first can be that of the evidence if the suspect has fired a gunshot in a specific situation, the second that of the evidence if the suspect was not involved in the shooting [2]. In many types of crimes (homicides, suicides, etc.), it is technically important to note if a given person has fired a shot with a firearm.

In the Brazilian Penal Code, the existence of questions or inaccuracies in forensic evidence leads to the non-conviction of a suspect, using the principle of in dubio pro reo [3]. Therefore, it is important that scientific analysis be subsidized by criteria and protocol that deviate subjectivity from the results, guaranteeing the correct application of the Law. The current analyses used by the Brazilian police force, particularly the residue analysis of lead, present questionable results (false positive and false negative). This situation arises from the limitation of the reagent used (sodium rhodizonate), which only identifies the chemical component $\mathrm{Pb}$. The exams were performed using Fritz Feigl's microanalytical technique [4]. However, this element is found in products other than those originating from shooting firearms, as well as the absence of an adequate protocol for collection and analysis of material from the hands of a suspect. There have been discrepancies in literature between the elapsed time of the alleged shooting and sample collection, being suggested that the maximum elapsed time should be between 3 and 4 hours. Hand cleaning is the third doubt in this type of crime, that is, if it would be feasible to collect samples from the hands of a suspect who has performed any type of cleaning between the shooting and sample collection.

The objectives of this study were: to develop a protocol for sample collection from the hands of a suspect, for analysis in SEM, of the main chemical elements that compose the primer of a cartridge $(\mathrm{Pb}$, $\mathrm{Sb}$ and $\mathrm{Ba}$ ); to determine the approximate permanence time of residues from a gunshot on the hands of a suspect; and verify if cleaning the hands of a suspect after the shooting, with products (such as water, alcohol, soap, detergent and hospital cleaning products), removes residue from a gunshot completely. A 
.38 caliber Taurus revolver with Brazilian Cartridge Company (CBC) ammunition was used. Sample collection was performed outdoors, at the Paraná Institute of Criminology. Blank samples, those collected shortly before the shooting, were collected. Samples were collected by removing a doublesided tape applied to the surface of the hand of shooter, immediately after the shooting. The samples were placed on stubs, sputtered in carbon for SEM analysis, on a FEI-Quanta 200 SEM with an accelerating voltage of $25 \mathrm{kV}$.

Our results show that the simultaneous presence of $\mathrm{Pb}, \mathrm{Ba}$, and $\mathrm{Sb}$ in the same particle (Figure 1), were found in $95 \%$ of our samples, immediately after the shootings. These are the common elements in GSR, and in the remaining $5 \%$, the presence of $\mathrm{Al}, \mathrm{Cu}, \mathrm{Fe}, \mathrm{K}, \mathrm{Mg}, \mathrm{Ca}, \mathrm{Si}, \mathrm{Ti}, \mathrm{Na}, \mathrm{Zn}$ and $\mathrm{Mn}$ was also found. Another important aspect related to the spherical morphology, which is evidence that this particle was formed at high temperatures, through the process of fusion at the time of shooting (Figure 1). The results of sample collection performed every hour, up to 12 hours after the shooting using the same weapon and ammunition with the shooter having washed his hands with soap only are still being processed. Therefore, the SEM/EDS technique is highly effective for GSR analysis, since it allows the morphologic identification and chemical element composition of individual particles. The identification of $\mathrm{Pb}, \mathrm{Ba}$, and $\mathrm{Sb}$ elements, simultaneously, in a spherical particle, is the only unquestionable evidence that a person has produced a gunshot, or has been next to someone who did, or even handled a firearm.

\section{References}

[1] E. Vermeij; Forensic Applications of Scanning Electron Microscopy, a brief overview in http://www.fei.com/uploadedfiles/documents/phenom/forensic_application_of_sem.pdf (2013) p. 3.

[2] F. S. Romolo and P. Margot; Identification of gunshot residue: a critical review. Forensic Science International (2001) V.15;119(2):195-211.

[3] http://www.planalto.gov.br/ccivil_03/decreto-lei/del2848.htm (2013).

[4] F. Feigel and V. Anger. Spot tests in organic analysis, $7^{\text {th }}$ Ed. Amsterdam, Elsevier, 1966.

\section{Acknowledgement}

This research work was supported by the FINANCIADORA DE ESTUDOS E PROJETOS (FINEP Contract 01100715/10 DOU 244 de 22/12/2010 and METROFOR N¹539/2010) - Brasil.

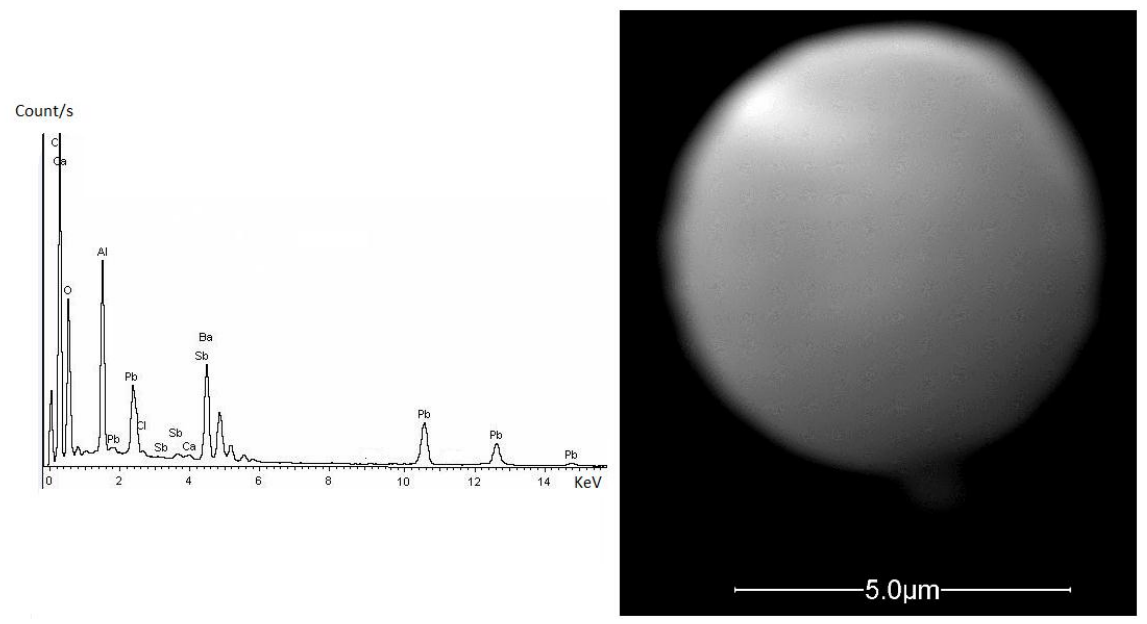

Figure 1. EDS Spectrum of a GSR particle and its micrographs immediately after shooting with a .38 caliber revolver. 